\title{
LAS LÁGRIMAS DE ODISEO
}

\author{
Miguel Castillo Didier \\ Universidad de Chile. Chile
}

Resumen: La expresión de la tristeza y el dolor con lágrimas es una característica del ser humano. En los poemas homéricos lloran los guerreros. Entre ellos, Odiseo. Este rasgo del héroe aparece también en la Odisea de Kazantzakis. El artículo muestra algunas de los momentos en que la emoción del personaje es manifiesta en llanto.

Palabras clave: lágrimas - Odiseo - Odisea - Kazantzakis

\section{ODYSSEUS' TEARS}

Abstract: The expression of sadness and pain with tears is a characteristic of human beings. In the Homeric poems the warriors cry. Among them, Odysseus. This feature also appears in the hero in the Kazantzakis' Odyssey. This paper presents some of the moments when the emotion of the character is manifested in tears.

Key words: tears - Odysseus - Odyssey - Kazantzakis

Recibido: 22.01.2014 - Aceptado: 22.04.2014

Correspondencia: Miguel Castillo Didier. E-mail: micastilgriego@gmail.com

Director Centro de Estudios Griegos, Bizantinos y Neohelénicos. Profesor Titular Universidad de Chile. Casilla 435-3 - Santiago - Chile 
T a conciencia de la muerte y la expresión de la tristeza y el dolor con lágrimas, que caracterizan al hombre entre los seres vivientes, están omnipresentes en los poemas homéricos. No sólo lloran las mujeres. Penélope llora en la Odisea y Andrómaca en la Ilíada. Pero lloran también los varones, lloran bravos y altivos guerreros, quienes no pocas veces nos conmueven con sus lágrimas. ¿Quién no recuerda el desconsuelo de Aquiles ante la muerte de Patroclo y su llanto junto al mar? Llora Odiseo, el duro héroe de la Ilíada, el hombre que en la Odisea enfrenta terribles embates de dioses y monstruos, en su obstinado intento de volver a su isla patria y a su hogar.

Cuando escuchamos el primer testimonio directo acerca del paradero de Ulises, de labios de Proteo, quien le habla a Menelao, podemos imaginar al héroe allá en los dominios de Calipso, sin poder salir de ellos. Lo vi, dice la deidad marina, "vertiendo / de los ojos copiosísimo llanto en la isla / y palacio que habita la ninfa Calipso". Tres veces más nos habla el poeta de las lágrimas de Odiseo, quien llora, mirando el mar desde unos cantiles. Allí "se le iba la vida en gemir por su hogar"2.

Y muchas veces más son las ocasiones en que el dolor y la emoción del héroe se expresan a través del llanto. ¿Cómo no recordar la escena en que Odiseo, en la corte del rey de los feacios, al oír al aedo cantar hechos de Troya, se cubre el rostro con la túnica para que no lo vean llorar; o la intensa aflicción del héroe cuando, al descender al mundo de los muertos, se impone de que su madre, Anticlea, no vive ya:

Mas entonces el alma llegó de mi madre difunta, que engendrara el magnánimo Autólico. Viva

\footnotetext{
${ }^{1}$ Homero: Odisea. Traducción José M.Pabón, Introducción C. García Gual, Editorial Gredos, Madrid 2000, IV, 554 y sig

${ }^{2}$ Ibídem, V, 152).

${ }^{3}$ Ibídem, VIII, 83-92 y 521.
} 
la dejé en mi mansión al salir para Troya sagrada;

brotó el llanto en mis ojos al verla e inundóseme el pecho de dolor ${ }^{4}$.

Refiriéndose a esta escena, escribe Standford: "A pesar de su brevedad y de su relativamente escasa importancia en el desarrollo del argumento, la escena es una de las más memorables de los poemas homéricos" 5 .

Llora con grandes sollozos Odiseo, junto a Telémaco cuando se reconocen; llora junto a Penélope, cuando al fin puede darse a conocer y es reconocido por ella; y llora junto a su padre, Laertes. Ante Argos, su perro moribundo, debe tratar de disimular las lágrimas, enjugárselas y volver la cabeza, para no delatarse y fracasar en el castigo a los pretendientes.

No es de extrañar el llanto de Odiseo, el héroe acaso el más humano de los héroes homéricos, pues, como escribía Lasso de la Vega: "Muchos más cercano a nosotros que los héroes de la Ilíada es Ulises, un eterno ideal de Humanidad, uno de los pocos Mitos perdurables del espíritu humano" ${ }^{6}$. Y Jorge Guillermo Llosa afirma: "Odiseo encarna al hombre en lo precario y en lo absoluto de su condición humana”.

No podemos recordar aquí todos los pasajes del poema homérico que registran ocasiones en que Ulises llora. Veremos que en la nueva Odisea, el poema de Kazantzakis, el personaje también llora, con lo cual muestra una de los rasgos con que aparece en la antigua epopeya.

Es en la rapsodia XXII del poema homérico, al terminar la matanza de los pretendientes, donde se produce el enlace entre la antigua y la nueva Odisea ${ }^{8}$. Pero Ulises no siente la paz y la alegría que esperaba naturalmente experimentar. Los reconocimientos o encuentros con los familiares más próximos se trocan en desilusión. Así sucede con su esposa, su hijo, su padre y su pueblo. Y la sensación de desencanto y de encierro que le producen su hogar y su entorno va acrecentándose a medida que pasan los días. Este desagrado, que recuerda el

${ }^{4}$ Ibídem, XI, 84-88.

${ }^{5}$ W. B. Standford: El tema de Ulises, p. 87.

${ }^{6}$ José Lasso de la Vega: "Ética homérica”, en R. Adrados, Fernández-Galiano, Luis Gil, Lasso de la Vega: Introducción a Homero, Ediciones Guadarrama, Madrid 1963, p. 315.

${ }^{7}$ Jorge G. Llosa: El libro de Odiseo, Prólogo de R. Latcham, Editorial Zig-Zag, Santiago 1965.

${ }^{8}$ Exactamente después del verso 479 de la vigésimo segunda rapsodia y este enlace es señalado con las primeras palabras del relato: "Cuando a los insolentes jóvenes Ulises hubo muerto..." 
del mismo personaje en el poema Ulises de Tennysson"; junto al afán de nuevas experiencias, que recuerda al Odiseo de Dante ${ }^{10}$; y la nostalgia de los viajes ${ }^{11}$, confluyen en el nacimiento de la idea de una nueva partida, sin retorno ya.

\section{Lágrimas por Itaca}

Pero alcanza todavía Odiseo a vivir la emoción de volver a contemplar su isla por tan largo años anhelada:

Ascendía el varón siempre errante y alas infinitas

y perfume de yerbas y traviesos pensamientos

su pecho embargaban;

subía, y cada vez mayor la blanca era de su patria se extendía,

y al fin, cuando pisó su pie la cumbre del desnudo monte,

el cuerpo pálido y esbelto apareció de su isla humilde.

Sus pupilas moviéronse, tratando de esconder en vano el llanto:

"Esta es la roca, el árido peñasco, que tanto deseé volver a ver;

me gusta”, murmuró; y de sus grandes párpados

las lágrimas cayeron ${ }^{12}$.

\section{Lágrimas por volver a ser mortal}

Hay dos ocasiones en que el llanto trae a Odiseo a su condición humana. Las cuenta con emoción en relato que de sus peripecias hace ante su familia, relación en cierta manera paralela a aquél que en el poema homérico hace ante Alcínoo y su corte. Tres grandes tentaciones tomaron forma de figuras femeninas en su vagar por los mares, tratando de regresar a su isla y su hogar. En cada una de ellas,

9 Sobre la relación entre los relación entre la Odisea y el Ulises de Tennysson, puede verse M. Castillo Didier: La Odisea en la Odisea Estudios y ensayos sobre la Odisea de Kazantzakis, Centro de Estudios Griegos Universidad de Chile, Santiago 2006-2007. La traducción española del poema de Tennysson en Oscar G. Ramos: La Odisea, un itinerario humano, Instituto Caro y Cuervo, Bogotá 1970.

${ }^{10}$ El pasaje de Dante en M. Castillo Didier: La Odisea en la Odisea.

${ }^{11}$ Pensamiento bellamente expresado por León Kukulas en el poema Pequeña Odisea, M. Castillo Didier: Un milenio de poesía griega, Centro de Estudios Griegos Universidad de Chile, Santiago 2004, p. 390.

${ }^{12}$ Kazantzakis: Odisea, Introducción, traducción, síntesis y glosario M. Castillo Didier, 2a edición, Tajamar Editores, Santiago 20013, I, 797-804. 
el haberse entregado habría equivalido a la muerte, pues a ésta se asimilaría el abandonar su objetivo: el retornar a Itaca.

En la isla de Calipso, Odiseo estaba perdiendo su calidad de mortal y estaba transformándose en un inmortal. Pero algo encuentra una mañana en la orilla del mar, que le recuerda quién es:

Pero una mañana tropecé entre los guijos desiertos con un despojo alargado que acaso dejó en seco por la noche la mar.

Levantélo lentamente y traté de recordar qué cosa fuera: hueso de un pez monstruoso, pata de un ave gigantesca, rama de un árbol del ponto, cayado de algún genio marino. Mas poco a poco fue amaneciendo en mi espíritu y me doy cuenta que un remo largo, muy amado, en mis desfallecientes manos sostenía.

Y mientras con suavidad lo acariciaba, los ojos nublados se aclararon:

al extremo del remo diviso la negra mano que lo manejaba, veo una quilla espumeante y la vela sobre un alto mástil. Vinieron en multitud los viejos compañeros con sus brazos tostados; vino también el mar y me golpeó y vaciló mi entendimiento, y de dónde partieron recordé y dónde ellos anhelan que yo vaya. ¡Ay! Era yo también un hombre ardiente y mi corazón bailaba y poseía patria, un hijo y una esposa y un navío veloz ${ }^{13}$.

Odiseo se pone febrilmente a hacer una balsa para partir. Le dice a la ninfa que mucho la quiere, pero debe partir. La diosa se lamenta pues ahora ha comenzado a humanizarse y sus marmóreos pechos se han entibiado. La balsa de pone en movimiento, mientras el canto dolorido de Calipso le parte el corazón.

${ }^{13}$ Ibídem, II, 138-151. 
Y cuando avanzaba, ya lejos, como saeta, en la ola de espumoso seno,

y el dolorido canto se perdió en la bruma del crepúsculo,

poco a poco la balsa se puso más pesada y se ladea:

las sombras la aplastaban: de mujer, de hijo, de patria se cargó,

y libre dejé a mi corazón conducirse a su agrado;

¡y éste estalló en sollozo amargo y otra vez se volvió humano! ${ }^{14}$

De haber cedido a la tentación de Calipso, habría pagado la inmortalidad con el precio de no ser hombre. "Había escogido voluntariamente el oscuro destino al que lo condenaba su libertad. Entonces descubrió lo poco que importaba ser rey y advirtió lo mucho que podía valer, aun en sus condiciones miserables, el ser un hombre entre los hombres" ${ }^{15}$. Las lágrimas son las acompañantes de ese descubrimiento.

\section{Lágrimas por volver a ser hombre}

En el relato de Odiseo sigue el encuentro con Circe. No hay aquí la intervención de Hermes ${ }^{16}$, que, en Homero, aconseja a Odiseo cómo actuar ante Circe y le da una hierba que le pondrá a salvo del filtro que le servirá la diosa maga. Ahora, Circe logra empezar a rebajarlo de su condición humana. Ulises intenta resistir, pero es vencido:

Mas cuando en el áureo alcázar húbeme bañado y sirvieron

la cena en el fresco jardín y espumaron las cráteras

y escuché la dulzura de la voz, volví a olvidar mi deber.

“¡Te bañaste, amado mío, has cenado y bebido, se abrieron

otra vez las venas

y luce tu gran cuerpo como de sólo veinte años, lozano y vigoroso;

ven para que juguemos en mi lecho y gocemos juntos!"

[...] Perdióse el sol, deslizóse el alma entre los rizos y esfumóse;

tomó forma de cerdo el rostro luminoso del humano

\footnotetext{
${ }^{14}$ Ibídem, II, 1184-189.

${ }^{15}$ J. G. Llosa: O. c., p. 100.

${ }^{16}$ Homero: Odisea, X, 274-309.
} 
y se apagó la llama que en vigilia temblaba entre las cejas.

Pálidas florecillas perfumadas, la vergüenza, virtud y bondad, cuán por encima arraigáis, ¡ay de mí! ¡cuán presto os marchitáis, y cuán hondo agarra dentro de nosotros nuestra madre arcilla! ¡Cómo olvidar, oh dios, la alegría que rugía en mis riñones al ver al alma, a la luz, a la virtud borrarse! Apretadas las manos y los muslos, rodábamos en la arena ígnea, trenza de víboras que se apegan en el sol y silban. Poco a poco, la razón enmudeció dentro de mí; se ahoga el fuego en el hogar y el espíritu emponzoñado se hace carne y hacia el vientre desciende.

Un día, la visión de un pequeño grupo humano, formado por una mujer con un bebé y unos amigos que comen, mirando el mar, lo hace recordar su condición de ser humano y su hogar allá en la isla:

Un día en que solo me revolcaba y gruñía en mi zahúrda, diviso un humo leve por la playa y una fogata encendida y unos hombres en cuclillas que por cañas partidas pasaban sartales de pescados y con cuidado sobre las brasas los volvían; y una mujer pálida, agachada, con un niño en el regazo, abrió su pecho y al punto se cogió del pezón el infante y. dichosa la madre, láctea-fuente, diole de beber. Los peces ya tomaban color rosa y golpea mis narices su perfume.

Se juntaron los hombres junto al fuego y se sentaron; y se allegó también la madre y tendió la mano a la compaña, y doble ración de pan, doble porción de pescado ella recibe. Con avidez comían, masticaban en silencio, contemplando la mar; se enjugaban los mostachos, la botella de vino inclinaban 
y bebían,

y pasaba al amigo del lado y después a la madre.

¡Pobre alegría mía inmortal, pan, comida, vino,

y ante ti que esté la mar azul y masticar lentamente,

y sentir más fuerte el alma y la carne renovarse;

Cuando han comido, se tienden los brazos abiertos al ígneo cielo,

y mueve la mujer suavemente su cuerpo de un lado a otro,

y un canto de cuna, lento, arrastrado, dulce, se difundió en el aire.

Vacías caían las palabras, se hundían en el limo de mi espíritu;

mas recibía en mi entraña el dulcísimo son y temblaban jadeantes

de ansiedad

las hojas pesadas de-gruesa-envoltura de mi corazón.

Sentía dolor, trataba de recordar, abríase-y-cerrábase mi pecho

- vasto patio, mar azulado, higueras, olivos, vides -

y una mujer de marmóreo cuello que amamantaba a un infante

¡ay de mí! si pudiera subir a una alta cumbre y aguda voz sacar!

Y repentinamente mi garganta se hinchó y mis sienes estallaron:

¡y otra vez me trajo a ti el llanto, estirpe humana! ${ }^{17}$

Y, una vez más, Odiseo corta árboles y construye una balsa para huir de la isla de Circe, la que a gritos lo apostrofa. exhortándolo a regresar.

\section{Lágrimas por volver a asirse a la tierra}

Después del episodio de Circe, navega Odiseo en la balsa y a poco lo golpea una tremenda tempestad que destruye la embarcación. Cae al mar rugiente, pero logra con esfuerzo alcanzar la costa, un lugar desconocido. La emoción lo domina a verse salvado una vez más. Es entonces cuando la dulce y pura figura de Nausícaa surgirá, como la tercera gran tentación: la de no volver a Itaca, lo que equivale a la muerte. Como en la Odisea homérica la tentación insinuada por el poeta ${ }^{18}$, aquí la clara tentación es vencida. Y Ulises verá en la joven una esposa para su hijo Telémaco.

${ }^{17}$ Kazantzakis: Odisea, II, 337-367.

${ }^{18}$ Refiriéndose a la breve despedida de Odiseo y de Nausícaa en la Odisea homérica, Standford escribe: "Algunos encuentran esta escena breve de despedida desilusionantemente brusca. 
Pero ya en la enloquecida aurora, destroza el rayo en velas y maderos mi embarcación y caigo a las rugientes aguas espumosas, apretando los dientes a fin de que mi alma no se ahogue.

Crucé la superficie de las olas con brazadas amplias, y, ya aclarando, agarraron mis manos las puntas de unas peńas:

"¡Vamos!, nuevamente tierra firme te cogí y otra vez echo raíces!”

Sollozando, riendo, me tendí en las piedras;

y se alzó entonces, ante mí la más dulce visión de la muerte ${ }^{19}$.

Al terminar el relato ante su familia, Odiseo ha terminado de cobrar conciencia de que la patria tan anhelada se le está convirtiendo en una prisión. Había logrado vencer tres formas de la muerte, como lo ha narrado. Pero ahora siente que su isla, su hogar, son una nueva imagen de la muerte.

Sellas sus labios amargos y no pronuncia ya palabra.

Contemplaba el fuego que se sumía, la llama que se marchitó, cómo se espolvoreaba y se extendía en el polvo la ceniza.

Vuélvese y mira a su mujer, divisa al hijo y al padre, y, estremeciéndose de súbito, suspiró y tocó sus labios con la mano;

ahora comprendía; también era la patria rostro dulce de la muerte.

Como de fiera que se cogió en la trampa, sus ojos giran y se mueven llameantes amarillos en sus profundas cuencas. Estrecho como aprisco pobre de pastor parecióle el palacio paterno,

una dueña de casa ya marchita también esa mujercilla;

'Nuestro corazón queda desilusionado y defraudado por el pago recibido [por Nausícaa]. La relación, se nos dice, es como 'como una frase musical dejada sin terminar"”. W. B. Standford: El tema de Ulises, p. 80.

19 Ibídem, II, 389-396. 
y el hijo, como anciano octogenario, todo lo pesa con cuidado, para hallar lo honrado y lo justo, lo deshonesto y lo injusto, y tiembla, cual si fuera la vida juiciosa y la llama fuera justa y también el espíritu, ¡el más preciado bien del hombre /de-ínpetu-de-águila!

Rió el atleta de-corazón-combatiente y estremecióse, y al punto la dulzura del hogar y la patria deseada y las doce deidades y la vieja virtud en el fogón honrado y el hijo mismo pareciéronle contrarios a su elevada raza. Se acaba y se marchita el fuego y débilmente lucían las cuatro cabezas y las lustrosas piernas de Telémaco; y lentamente en el silencio trémulo estallan desesperanzados, en aniego, como caídas de agua, los sollozos de Penélope. Tenso saltó el hijo al trono de su madre y se detuvo y con muda piedad tocó sus hombros albísimos.

Miró a su padre en la penumbra torvamente y se horripila, pues a los últimos destellos de la llama decaída, púrpuras, azulados, amarillos, distingue sus ojos centellear impasiblemente, y ya se perdía su cuerpo salvaje en las tinieblas.

\section{Lágrimas por el desencanto}

La gran decisión no es fácil. El alma de Odiseo está conmocionada por sentimientos encontrados. Una vez más, vendrán las lágrimas.

Camina a grandes pasos en silencio el arquero, destraba el pasador; atraviesa los atrios y quedamente sale hasta el camino. Unos lo encontraron al subir el sendero de los muertos; otros lo vieron tranquear por las rocas de la playa; 
y un visionario mudo lo divisó a la medianoche nadar y hablar ocultamente con los genios marinos.

Y sólo un niño pequeño en su sueño lo vio

junto a la espuma del mar sentarse doblado a llorar ${ }^{20}$.

\section{Lágrimas al despedirse de Helena}

Finalmente, Ulises partirá desde Itaca, en viaje sin retorno, con unos cuantos amigos. Llegar a Esparta, donde encontrará a Menelao, senil y decadente. Lo ayuda a sofocar una sublevación. A Helena ${ }^{21}$ la halla, por el contrario, en plena energía, cansada de su marido y ansiosa de salir a la ventura. Se ponen de acuerdo con Odiseo y ambos parten en un viaje incierto que luego toma rumbo a Creta. Allí reina Idomeneo, decadente y tiránico como Menelao. Una revolución está en marcha y a ella se une Odiseo. Helena coadyuva a la acción. Por los mismos días llegan oleadas de bárbaros rubios, que ya habían visto cerca de Esparta. Uno de ellos enamora a Helena, que se queda con él en Creta, cuando la revolución triunfa, y Odiseo se dispone a partir nuevamente.

Después de sepultar a Fida, una heroína cretense, y a Stridás, uno de los amigos que salieron de Itaca con Odiseo, éste se despide, emocionado, de la isla, y de Helena, que espera un hijo.

¡Adelante! ¡Terminó ya nuestra jornada en Creta!

[... ¡Un novel sol amaneció, también comienza una jornada nueva!

Dijo así. Y deja vagar en torno una lenta mirada de despedida:

nunca más a los hombres, las colinas, el arroyo, la dulzura

de la isla señorial contemplar sus ojos volverán.

Avanza y una piedra arroja tras de sí y el golpe da $e^{22}$

en su pensamiento, dirías que cayó en cisterna sin fondo.

Y cuando ávida la vista giraba y daba mudo adiós,

${ }^{20}$ Ibídem, II, 429-464.

${ }^{21}$ Sobre la presencia de esta mujer en el poema, puede verse el ensayo "Helena: la perennidad de la belleza en "La Odisea en la Odisea", o. c.

22 En la creencia popular, el lanzamiento de una piedra hacia atrás al abandonar un lugar simboliza la voluntad de no volver más, el dejar atrás lo pasado en él. 
de repente la mirada hechizada se posó en la-de-arqueadas-cejas.

Junto al hombronazo de melena blonda lucía satisfecha, como una tierra húmeda sobre la cual cae el sol y vapor exhala.

“¡Helena!” gritó el-de-gran-corazón, y se trizó su pecho.

Levanta con pereza los párpados cansinos la-de-cejas-espesas

y sonrió, y “¡Adiós!”, responde, entreabriendo los labios.

Con dulzura da la mano Odiseo a la-bañada-por-el-sol.

"Conceda el dios que juega con la tierra y mezcla a los humanos,

que des a luz un hijo, que equilibre con firmeza las dos

vastas alas

que flanquean con doble ímpetu los límites del hombre:

¡el corazón bárbaro, embriagado, y el pensamiento que, altivo

$$
\text { / y despejado, }
$$

le sujeta las bridas para que al caos no se precipite!

¡Helena, amado rostro de la tierra, nunca más

mis ojos te verán ni te tocarán mis manos toscas;

naciste espuma, fulguraste y te apagas en la cima de mi espíritu!"

Dijo. Y vuelve la cara para que el llanto no se manifieste ${ }^{23}$.

\section{Lágrimas por el perro Argos}

El episodio del encuentro del reconocimiento de Odiseo por su perro Argos es uno de los pasajes más hermosos del poema homérico. A Odiseo - expresa Highet - "nadie lo reconoce en su hogar, excepto su viejo perro, que lo saluda y muere de alegría entre sus piojos. ¿No es acaso la muerte de un perro sarnoso en un estercolero el colmo mismo de la inmundicia? No. El último gesto de Argos es un gesto de generosa y abnegada nobleza, y sigue siendo una figura heroica en nuestros corazones" ${ }^{24}$. Oscar Gerardo Ramos ha podido escribir así sobre aquel animal inolvidable, del que la escultura no nos dejó imagen: "Argos quedó esculpido en una piedra de hexámetros, con estampa más antigua, más

${ }^{23}$ Ídem, VIII, 895-919.

${ }^{24} \mathrm{G}$. Highet: La tradición clásica Influencias griegas y romanas en la literatura occidental. Traducción A. Alatorre, F. C. E., México 1954, vol. II, p. 319. 
solemne, más fúlgida que la que muestran los leones del portalón de Micenas. Porque Homero lo había burilado en roca de cántico, la estética helenística no se atrevió a plasmarlo en mármol huidizo" 25 .

Argos, viejo, enfermo es el único que reconoce a Odiseo, sin necesidad de un prueba. Como escribe Vernant, "contrariamente a los humanos, para advertir su presencia [la de Ulises], no necesita sémata, signos. Sema: la palabra clave del reconocimiento como lo mostraron pertinentemente muchos comentaristas de la Odisea [...]. El reconocimiento de su amo por parte de Argos es, por el contrario, inmediato. El animal lo experimenta en el acto, sin tener que apoyarlo con pruebas o demostraciones"26.

Bien a Ulises notó que hacia él se acercaba y, al punto, coleando dejó las orejas caer, mas no tuvo fuerzas ya para alzarse y llegar a su amo. Éste al verlo desvió su mirada, enjugóse una lágrima, hurtando prestamente su rostro al porquero, y al cabo le dijo..." ${ }^{27}$.

Y Odiseo interroga a Eumeo sobre ese pobre perro. Se adivina en su pregunta su amor por el perro que ve en tales malas condiciones y su emoción por el gesto de amor del animal, amor al que no puede en ese momento corresponder.

En un verso y medio, el poeta nos cuenta el fin del fiel animal tras haber reconocido a su amo:

Tal habló, penetró en el palacio de buena vivienda y derecho se fue al gran salón donde estaban los nobles pretendientes; y a Argos sumióle la muerte en sus sombras no más ver a su dueño de vuelta al vigésimo año ${ }^{28}$.

${ }^{25}$ O. G. Ramos: La Odisea Un itinerario humano, Instituto Caro y Cuervo, Bogotá, 1970, pp. 118-119.

${ }^{26}$ F. Frontisi-Ducroux y J. P. Vernant: "En el espejo de Penélope”, en En el ojo del espejo. Traducción Horacio Pons, F. C. E., Buenos Aires 1999, pp. 197.198.

${ }^{27}$ Homero: Odisea. Traducción J. M. Pabón, Introducción C. García Gual. Editorial Gredos, Madrid 2000, XVII v. 290-305.

${ }^{28}$ Ibídem, XVII v. 324-327. 
En el poema de Kazantzakis, Odiseo recuerda a Argos en la rapsodia XXI cuando al llegar a la punta sur de África, al término de su inmensa peregrinación, ve el mar de nuevo y lo saluda como si fuera su perro:

“¿Enhorabuena ante mi casa te encuentro, mi perro viejo y fiel;

ola mía, no me has olvidado todavía y con ternura me ladras!”

Salta y agachado lo acaricia, toca la blanca mota;

se acordó de otro fiel animal, hace ya miles de años,

cuando agitaba su rabillo en su patio mancillado,

y se lanzó a darle bienvenida, despreciando a los pretendientes

/ enemigos.

“¡Argos!”, llamó ahora en su pensamiento, y el perro brotó

lleno de lodo desde la tumba, moviendo su lomo ${ }^{29}$.

Esta aparición de Argos en el recuerdo de Odiseo, queda sin continuación en esta rapsodia. En la rapsodia XXIII, el peregrino, sintiendo próximo su fin, llama a todos los que lo amaron, a todos los que él conoció. Por las palabras de Argos, sabemos que a él fue el único al que llamó, de entre las personas de Itaca.

En la rapsodia vigésimo tercera, cuando Odiseo llama a todos los que lo amaron, Argos, en su tumba, oye un silbido del amo y sale de su sepulcro. En este pasaje se recuerda el correspondiente de Homero, pero en forma muy especial, como veremos; pues se suponen hechos que no están en el poema antiguo. Este "agregado" al relato homérico es lo que permite que el perro exprese amor y ternura con una intensidad y delicadeza acaso no igualada en el vasto texto kazantzakiano, con sus numerosísimos personajes e innumerables episodios. La lágrima que Odiseo se enjugó en Homero llega a ser los sollozos que se bebe ahora.

Ahora, al partir desde su tumba en Itaca, respondiendo al llamado de Odiseo, Argos todavía tiene sangre que le sacaron las uñas de Ulises, cuando "lo agarró sin piedad", para que no ladrara de alegría y lo delatara ante los soberbios pretendientes. Los ojos del viejo perro distinguieron y reconocieron al punto al amo, en cuanto lo vieron, y el animalito se arrastró gimiendo, "con queja inexpresable", a entremeterse en sus pies; pero el terrible amo "se bebió los

${ }^{29}$ Ibídem, XXI, 176-189. 
sollozos en secreto" y lo asió por el cuello ${ }^{30}$. Y entonces fue cuando se derrumbó muerto el fiel animal, y al morir aún alcanzó a mover la cola por la dicha de haber alcanzado a ver a su dueño. En su tumba, los rasguños se volvieron collar de coral y las lágrimas de Odiseo, una perla. Con esta bella imagen, el poeta expresa la ternura de Argos, su amor por el amo al que tanto esperó. El perro es el más desvalido, el de vida más breve, de cuantos aguardan el regreso de Ulises. Si éste no llega, Argos no podrá vivir mucho más. Pero Odiseo llega y en la intensa emoción del reconocimiento, el animalito quiere expresar su alegría. No puede saber que no es oportuno hacerlo. Y el propio amo amado lo lastima, sin querer. Sin embargo, Argos no se resiente; al contrario. Y en sus despojos, esas lastimaduras de convierten en un collar de coral y en hermosa perla.

Ahora, en su tumba, escucha allá el llamado de Ulises, y se siente ufano, porque el amo "en la gran necesidad", solamente a él lo ha invocado entre los habitantes de Itaca, y no a su padre o a su hijo. ¿Cómo sabe esto el perro? La poesía y el amor no necesitan explicaciones. El hecho que Argos lo sabe es una realidad poética. El perro piensa regocijarse con Odiseo, si el motivo de la llamada es un acontecimiento feliz; pero si el amo llama porque está en agonía, se tenderá a sus plantas como un blando cojín. Y parte entonces hacia el sur.

Como se ve, el pasaje comienza con la llegada del perro a la ribera helada desde donde hay que salir a buscar la barca en la que navega Ulises, y termina con su partida desde su tumba en Itaca. Más adelante, en el poema (versos 12911294), sabemos que Argos llega donde Odiseo y alcanza a lamerle los pies y logra entibiárselos un poco, pero aquél no alcanza a acariciar al pobre-animal-en-loshuesos, pues su fragata-de-hielo, la última embarcación del navegante, se remece y se inclina en ese momento.

Este es el pasaje en que el perro Argos se nos aparece, a tantos años de Homero. Y notemos que el poeta ha santificado al animalito; nos habla de su "santo cuello", utilizando un término que Odiseo sólo usa cuando recuerda "la santa sonrisa" de su madre y cuando habla del "rostro santificado" de su padre muerto.

Llegaban a la orilla, refrescábanse, los lejanos-invitados, se unían con la espuma y navegaban, volaban con los petreles,

\footnotetext{
${ }^{30}$ Anotamos la curiosa coincidencia de que Jean Giono en Naissance de l'Odysée, obra publicada en 1937, el viejo y fiel perro Argos aparezca reemplazado por una urraca domesticada. Reconoce al amo y comenzar a chillar, por lo que Odiseo, para no ser sorprendido por Antínoo, la estrangula con sus manos. J. Giono: Naissance de l'Odysée, Bernard Grasset, París 1937.
} 
y cuando la gran ribera se quedó vacía, un pobre

$$
\text { / perro-en-los-huesos }
$$

se estremeció con ansia, husmeando el aire.

De muy lejos partió, desde las costas de la fresca patria.

En el hoyo en que por años se podría su osamenta vieja, oye el llamado del amo y el gran requerimiento; y salta moviendo el rabo y parte a lo largo de los aires. Aún sangre tenía el cuello tibio de cuando las uñas del señor lo agarraron sin piedad en uno de los patios, para que de gozo no

/ ladrara

y los soberbios pretendientes no supieran que llegó

/ el dueño-de-casa.

Bien distinguieron los ojos legañosos a Odiseo, y se le arrastró, gimiendo, con queja inexpresable, y temblando se entremetió en sus pies y los talones le lamía; pero el terrible cazador se bebió los sollozos en secreto, asió ese cuello sucio que seguía aullando, y nuestro fiel lebrel muerto se derrumbó, y aún el triste rabo se estremecía por la dicha.

Coral volviéronse los rasguños, orgullo del santo cuello, y en el medio una perla, la lágrima del amo; lanza las piedras de la tumba, ladra sorprendido, sus húmedas narices huelen el viento y tiemblan. En lo profundo del Hades oyó un silbido, y huellas amadas llenaron la tierra y el aire y agitaron el mar; y de nuevo fue un penacho su magra cola, le volvieron unos / dientes albos

y se lanza hacia el mar: “QQué alegría! En la gran necesidad ni al viejo padre llamó ni invocó a su gran hijo; ¡de toda su isla patria, sólo a mí me eligió y me recoge! 
O mi amo se casa o lucha-con-la-muerte;

vamos: comer y festejar, si hay mesas preparadas,

y si se trata de agonía, mis patas extender

¡y como un grueso cojín tenderme a las plantas del amo!”

Y el viejo perro, tiritando sobre sus garras roídas,

olió la brisa por todo el contorno y se lanzó hacia el $\operatorname{sur}^{31}$.

\section{Lágrimas por su padre}

Ya en la última etapa de su viaje, navegando en un navío de cuero de foca que le hicieron los últimos hombres que vio, los habitantes de un pueblo polar que fue devorado por el mar, viene Caronte ${ }^{32}$, en figura de un anciano de albo cabello, enteramente igual a Odiseo, y se sienta en el otro extremo de su barca. Ésta es la postrera de las variadas formas en que Caronte se presenta en el poema. En la soledad total y el frío intenso, el sueño le viene al navegante:

Se cansó, inclinó la cabeza y el sueño lo invadió:

y enfrente, el anciano Caronte lo contemplaba con anhelo mudo, como un hermano al hermano menor que volvió de otras tierras, y le sonrió el-de-siete-almas y se sumió en el sueño.

Allá lejos comienza una lluvia torrencial y coge en sus redes la planicie;

los granos sembrados se dilatan y se llenan de una leche gruesa, y los muertos que yacen desnudos en el suelo comienzan a hincharse.

En el sueño son las piedras cristalinas y la tierra es transparente y el-de-los-mil-sufrimientos se inclina y dobla y contempla

${ }^{31}$ Odisea K, XXIV, 738-771.

${ }^{32}$ La presencia de Caronte es constante en la Odisea de Kazantzakis. Aparece y reaparece ante Odiseo en diversas circunstancias y bajo variados aspecto.s. Sobre el tema de Caronte en la tradición popular neogriega, ver O. Omatos: "Del Caronte barquero al Jaros neohelénico", Veleia, No 7 , 1990; M. Alexiou: "Modern Greek Folklore and its relation to the past. The evolution of Charos in Greek Tradition", Proceedings of the 1975 Symposium of Modern Greek Studies, University of California Press; "Katábasis: el mundo de los muertos en la Odisea" y "Caronte: supervivencia y metamorfosis" en M. Castillo Didier: La Odisea en la Odisea, o. c. 
a los difuntos;

mira a su padre que yace tendido y su corazón se triza:

nunca en vida de su viejo le dijo una palabra dulce,

y ahora en los confines de este mundo, en su dormir,

lo recuerda y llora.

Poco a poco se calmó la lluvia, y el arquero, agachado, aspiraba el fuerte olor a tierra ${ }^{33}$.

${ }^{33}$ Odisea, XXIII, 500-511. 


\section{Referencias bibliográficas}

Adrados, R. (1983). Introducción a Homero. L. Gil Editor. Madrid: Ediciones Guadarrama.

Castillo Didier, M. (2004) Un milenio de poesía griega. Santiago: Centro de Estudios Griegos. Universidad de Chile

Castillo Didier, M. (2007). La Odisea en la Odisea Ensayos y estudios sobre la Odisea de Kaznatzakis. Santiago: Centro de Estudios Griegos. Universidad de Chile.

Castillo Didier, M. (1996). La Odisea y el exilio: itinerarios del saber y del dolor. Apartado de Boletín de la Academia Chilena de la Lengua, No71. Santiago: Academia Chilena de la Lengua.

Chosa, J. G. (1965) El libro de Odiseo, Prólogo de Ricardo Latcham, Santiago: Editorial Zig-Zag.

Choza, J. y P. (1996). Ulises, un arquetipo de la existencia humana. Barcelona: Editorial Ariel.

García Gual, C. (2000). "Introducción” a Homero: Odisea. Traducción J. M. Pabón. Madrid: Editorial Gredos.

Homero. (2000). Odisea. Traducción J. M. Pabón. Madrid: Editorial Gredos.

Homero. (1954). Obras Completas. Traducción L. Segalá Estalella. Prólogo A. Marasso. Buenos Aires: Editorial El Ateneo.

Kazantzakis, N. (2010). Odisea. Introducción, traducción, resumen en prosa, glosario, bibliografía, Post Scriptum, M. Castillo Didier. $3^{a}$. ed. Santiago: Tajamar Editores.

Lasso de la Vega, J. (1983). "Ulises y su mundo de ideales éticos", en R. Adrados y otros L. Gil Editor: Introducción a Homero. Madrid: Ediciones Guadarrama.

Manguel, A. (2010) El legado de Homero. Traducción Carmen Criado Fernández. Barcelona: Random House Mondadori S. A.

Omatos, O. (1993). “Odiseo en la poesía neohelénica”. En Veleia No 10 Vitoria: Universidad del País Vasco.

Paвón, J. M. (1947). Homero. Barcelona: Editorial Labor. 
Quiroz, R. (2004). Nikos Kazantzakis Dimensiones de un poeta-pensador Santiago: Centro de Estudios Griegos Universidad de Chile.

Ramos, O. G. (1970). La Odisea: un itinerario humano. Bogotá: Instituto Caro y Cuervo.

Romilly, J. DE. (1997). “¿Por qué Ulises?”, en J. de Romilly: Sinandisis me tin Arjea Helada Encuentros con la Grecia Antigua. Traducción al griego K. Miliaresi y B. Athanasíu. Atenas: Editorial To Asti.

Standford, W. S. (2013). The Ulysses Theme. Edición de Alfonso Silván, traducción de B. Afton Beattie y Alfonso Silván. Madrid: Editorial Dykinson. 